TI 2011-129/3

Tinbergen Institute Discussion Paper

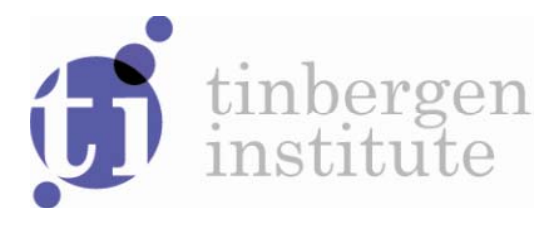

\title{
Regional Population-Employment Dynamics across Different Sectors of the Economy
}

Thomas de Graaffa,b

Frank G. van Oortb,c

Raymond J.G.M. Florax ${ }^{a, d, e}$

a Department of Spatial Economics, Faculty of Economics and Business Administration, VU University Amsterdam, Amsterdam, The Netherlands;

b Netherlands Environmental Assessment Agency, The Hague, The Netherlands;

c Department of Economic Geography, Utrecht University, Utrecht, The Netherlands;

a Department of Agricultural Economics, Purdue University, West Lafayette, IN, United States;

e Tinbergen Institute. 
Tinbergen Institute is the graduate school and research institute in economics of Erasmus University Rotterdam, the University of Amsterdam and VU University Amsterdam.

More TI discussion papers can be downloaded at http://www.tinbergen.nl

Tinbergen Institute has two locations:

Tinbergen Institute Amsterdam

Gustav Mahlerplein 117

1082 MS Amsterdam

The Netherlands

Tel.: +31(0)205251600

Tinbergen Institute Rotterdam

Burg. Oudlaan 50

3062 PA Rotterdam

The Netherlands

Tel.: +31(0)10 4088900

Fax: $+31(0) 104089031$

Duisenberg school of finance is a collaboration of the Dutch financial sector and universities, with the ambition to support innovative research and offer top quality academic education in core areas of finance.

DSF research papers can be downloaded at: http://www.dsf.nl/

Duisenberg school of finance

Gustav Mahlerplein 117

1082 MS Amsterdam

The Netherlands

Tel.: +31(0)20 5258579 


\title{
Regional Population-Employment Dynamics across Different Sectors of the Economy*
}

\author{
Thomas de Graaff ${ }^{a, b, \dagger}$, Frank G. van Oort ${ }^{b, c}$ and Raymond J.G.M. Florax ${ }^{a, d, e}$ \\ ${ }^{a}$ Department of Spatial Economics, VU University Amsterdam, Amsterdam, The Netherlands \\ ${ }^{b}$ Netherlands Environmental Assessment Agency, The Hague, The Netherlands \\ ${ }^{c}$ Department of Economic Geography, Utrecht University, Utrecht, The Netherlands \\ ${ }^{d}$ Department of Agricultural Economics, Purdue University, West Lafayette, IN, United States \\ e Tinbergen Institute, Amsterdam, The Netherlands
}

September 13, 2011

\begin{abstract}
An important subset of the literature on agglomeration externalities hypothesizes that intrasectoral and intersectoral relations are endogenously determined in models of local and regional economic growth. Remarkably, structural adjustment models describing the spatio-temporal dynamics of population and employment levels or growth traditionally do not include intersectoral economic dynamics. This paper argues and shows that allowing for economic linkages across sectors in these models adds considerable value, especially in forecasting. An econometric model of population-employment dynamics in which sectoral variations in economic development are explicitly taken into account is applied to a large urban planning policy proposal in The Netherlands. The empirical analyses suggest that population dynamics are largely exogenous, population changes drive employment in particular in the industry and retail sectors, and employment in all sectors depends strongly on intersectoral dynamics. Intersectoral dynamics appear as important drivers of regional sectoral employment changes; they are even more important than population changes, and their effect shows up clearly even within the Dutch institutional context where strict regulatory housing and planning restrictions are enforced.
\end{abstract}

Keywords: Spatial planning, population-employment dynamics, sectoral decomposition, agglomeration externalities, spatial econometrics

JEL-classification: C31, R11, R41, R58

\footnotetext{
${ }^{*}$ A previous version of this paper was presented at the conference "Urban Development: Patterns, Causes, Foundations and Policy" organized by the Institute for Housing and Urban Development Studies (IHS), the Erasmus University Rotterdam and Utrecht University (Department of Economics and Faculty of Geosciences), in Rotterdam, The Netherlands, 13-14 December 2010. The authors would like to thank the conference participants, the journal reviewers and the editors for useful comments and discussion.

${ }^{\dagger}$ Corresponding author. Tel. +31-20-5986092. E-mail: t.de.graaff@vu.nl.
} 


\section{Introduction}

In the mainstream regional science literature there is a variety of approaches focusing on explaining and forecasting regional growth patterns, be it in terms of gross domestic product, productivity, employment, or migration and population. Oftentimes, more or less elaborate interregional computable general equilibrium models are used. These models are as a rule based on traditional microeconomic principles and they often include the impact of urban amenities, as originally pioneered in the work of Roback (1982) and Graves (1983). Increasingly, the New Economic Geography theory also provides motivation for the use of various modeling efforts. In addition, there is also a modeling tradition based on a substantially more succinct representation of regional development going back to the early work of Carlino and Mills (1987). In this tradition a system of two equations is used to model the interdependent processes of population and employment growth in the context of dynamic adjustment processes. However, qualitative assessments of the empirical literature based on the original Carlino-Mills setup have shown that the conclusions from this literature are rather inconclusive (Sohn and Hewings 2000, Bollinger and Ihlanfeldt 2003). In addition it should be noted that intrasectoral and intersectoral agglomeration economies are not strongly represented in this literature, because usually only "people follow jobs" and "jobs follow people" conceptualizations of causal dependence are allowed for.

In explaining and trying to summarize the empirics of the population-employment dynamics literature, quantitative techniques such as (quasi-)experimental simulations and meta-analysis have been used. Hoogstra et al. (2005) used a meta-analysis to show that the question whether people follow jobs or jobs follow people does not have an unambiguous answer. The outcomes of the different studies are not easily summarized in terms of magnitude, because the measurement units of the dependent and independent variables as well as the functional forms differ across studies. Instead of a meta-regression on the magnitude of the effects, the authors use a multinomial logit setup classifying studies, or study results in most cases, as: (1) no statistically significant causal direction is apparent, (2) "jobs follow people" dominates, (3) "people follow jobs" is the primary mechanism, and (4) bidirectional causality is found. In a descriptive sense they find that from their total sample of 308 study results taken from 37 Carlino-Mills-type studies published between 1987 and 2003, 26 percent is inconclusive in terms of the dominating mechanism, 32 percent points to "jobs follow people", 28 percent identifies "people follow jobs", and 15 percent establishes some form of bidirectional causality. This is obviously rather 
disenchanting and the authors therefore go on to analyze whether these differences can be systematically associated with variations in the covered geographical area, time period and different population/employment groups, methodological features of the studies, and publication status. They find that generally the empirical evidence for "jobs follow people" is much stronger than for "people follow jobs", and finding the latter is strongly associated with the use of rather large-scale data pertaining to the United States, at the level of states or Bureau of Economic Analysis (BEA) regions. There is evidence suggesting that the results for the United States (US) may be markedly different from results obtained for other countries, especially in Europe. Finally, they also establish that choices with respect to various aspects of the methodological design of the studies (for instance, levels or growth rates, standardization by area, and high versus low density regions) have non-negligible impact.

In a quasi-experimental meta-analysis Hoogstra et al. (2011) use a rich dataset for The Netherlands comprising 392 settlements of approximately $25 \mathrm{~km}^{2}$, comparable to US census tracts. They generate "artificial" datasets from an existing settlements database during the time period 1988-2002, and in doing so generate their own study results. Subsequently, they perform a multinomial meta-regression similar to Hoogstra et al. (2005) and determine the impacts of varying time periods, urban density, different sectors, different practices of standardization, the specification of the spatial weights matrix, and the specification and estimation of spatially lagged dependent variables. A total of more than 4,000 experiments were performed, and many of the above-mentioned conclusions of the meta-analysis were corroborated. In addition Hoogstra et al. (2011) show that it is crucial to control for spatial dependence in the context of structural adjustment models. Empirical results using the generalized spatial three-stage least squares estimator (GS3SLS) developed by Kelejian and Prucha (2004) are notably different from those simply based on the standard 2SLS or 3SLS estimator.

We make various contributions to the above introduced dynamic adjustment literature. One is that we use a loglinear specification in terms of growth rates of regional population and employment shares, which contributes substantially to the stability and stationary of the model results. Second, we allow for different sectors which are explicitly modeled as separate equations, thereby introducing a third causal mechanism that we label "jobs follow jobs". Arguably, this mechanism can be associated with backward linkages (Venables 1996), but it is equally valid to associate the mechanism with the prevalence of agglomeration economies associated with intrasectoral and intersectoral economic dynamics, like labor mobility, spin-off dynamics, knowledge spillovers or skill-relatedness localization and urbanization economies (Rosenthal 
and Strange 2001). Third, we use a scenario analysis technique to produce regional population and employment forecasts, similar to the projection of spatial outcomes of population and employment growth in US metropolitan areas by Carruthers and Mulligan (2007). Finally, our model specification constitutes a relatively simple computable general equilibrium model as opposed to much more involved New Economic Geography models and full-blown interregional general equilibrium models. This relatively simple model nevertheless allows us to control for spatial spillovers in the endogenous variables and incorporate spatially correlated errors. Our model is estimated using the GS3SLS estimator of Kelejian and Prucha (2004), and incorporates endogenous spatial spillovers as well as intrasectoral and intersectoral linkages. ${ }^{1}$ We conduct our research on The Netherlands, and in particular on the case study areas of Almere and Amsterdam, for several reasons. First, the case of Almere is particularly suitable for our chosen model setup, because this relatively large-scale project is built from scratch in the vicinity of a large, existing conurbation. The plan originally only had a housing component, which constituted the exogenous policy-shock, with unknown employment impacts that are determined by population-employment dynamics and agglomeration forces. Our primary goal is to identify the future employment impacts of the exogenous housing policy. Second, housing and planning regulations are particularly tight in The Netherlands. We therefore test whether intersectoral linkages make a significant contribution to the projected development, even in the context of stringent regulatory control. Finally, The Netherlands is particularly data-rich, which allows for the construction of long time series of past and predicted local employment and population observations, concurrently controlling for a diverse set of conditioning variables.

The organization of the remainder of this paper is as follows. In Section 2 we provide more detail on the economic rationale behind the significance of sectoral linkages for agglomeration economies, and the way in which these can be incorporated in structural adjustment models. Section 3 summarizes the empirics of research on structural adjustment models. Section 4 provides background on how these models can be utilized in urban planning and regional development policies. The theoretical model and the econometric specification of a structural adjustment model that includes sectoral dynamics is explained in detail in Section 5. Section 6 provides a description of the data as well as the overall results for an analysis of municipalities in The Netherlands using data for the period 1996-2008. In addition we identify marginal effects

\footnotetext{
${ }^{1}$ As mentioned above, there is a quite voluminous recent literature dealing with population-employment models (see, amongst others, Carruthers and Vias 2005, Carruthers and Mulligan 2007, 2008). However, usually these studies employ more traditonal two-stage least squares (2SLS), three-stage least squares (3SLS) or generalized spatial 2SLS methods.
} 
of an annual (future) exogenous change to the housing stock in the city of Almere, which is part of the Amsterdam conurbation, during the forecast period 2008-2028. Section 7 concludes.

\section{Sectoral dynamics and agglomeration economies}

Recent regional and urban economic theory suggests that regional economic policies aimed at improving economic performance should be targeted at facilitating agglomeration economies (McCann and van Oort 2009). Agglomeration economies build on the notion of spatial externalities or spatial spillovers. Spatial externalities (or spillovers) occur if the behavior of an economic actor, typically a consumer or producer, increases the performance or welfare of another consumer or producer without a deliberate intention to generate the spillover effect, and without any compensatory payment (Henderson 1997). Spatially bounded externalities are related to location decisions of consumers and firms within the context of an economic network. The driving mechanism in agglomeration economies follows from the increased size of urban agglomerations leading to increased productivity, which will attract people to migrate to larger agglomerations (Fujita et al. 1999). This migration will cumulatively cause higher productivity levels and higher economic growth, which will ultimately result in a Myrdal-type process of cumulative causation. Arguably, in addition to these centripetal forces, dispersion or centrifugal forces are at work as well. However, after a certain threshold of transport costs and freeness of trade has been reached, the strength of agglomeration economies may outweigh the dispersion factors.

The empirical evidence for the existence of agglomeration economies is strong. In their famous overview paper, Rosenthal and Strange (2004) showed that a doubling in the size of an urban agglomeration leads to an increase in productivity of approximately 3 to 11 percent. In a meta-analysis of the empirical agglomeration literature, Melo et al. (2010) used a sample of 34 studies on agglomeration economies and identified 729 estimated values of the productivity increase with an upper bound as high as 29 percent. Similarly, in a meta-analysis considering 31 (partly different) empirical studies and focusing on levels rather than on growth, de Groot et al. (2009) concluded that the empirical results provide "strong indications for sectoral, temporal and spatial heterogeneity" in observed agglomeration economies. This observation is corroborated in the qualitative assessment of the most recent empirical agglomeration literature by Beaudry and Schiffauerova (2009).

Even although the empirical evidence for the existence of agglomeration externalities is 
conclusive, there is substantially less clarity regarding the microeconomic foundations of the agglomeration phenomenon (Duranton and Puga 2004, Puga 2010). These foundations can be related to firm-level advantages, such as co-location with subcontractors reducing transport costs, or to consumer advantages of having a larger variety of products to choose from and less search costs. In our conceptual framework, spatially bounded externalities are related to location decisions of consumers and firms within the context of an economic network. Remarkably though, structural adjustment models do not pay explicit attention to inter-firm linkages within and across sectors as explanations of regional dynamics. There are, however, several reasons why these sectoral linkages may lead to local development in addition to the traditional set of causes for population-employment dynamics, and it is therefore useful to incorporate inter-sectoral linkages in a structural adjustment model. We discuss these reasons in more detail.

First, agglomeration economies differ over sectors. A large average firm size or a large initial number of local firms may cause a high level of local factor employment to propel into the development of external economies within the group of local firms in a particular sector. These agglomeration externalities are termed "localization economies". The strength of these local externalities typically varies, and they tend to be stronger in some sectors and weaker in others (Duranton and Puga 2000). The associated economies of scale comprise factors that reduce the average cost of producing outputs in that locality. Alternatively, sectoral variety may reflect external economies passed on to enterprises as a result of benefits from the existence of a large-scale operation and interplay of various sectors. Specifically, sectorally related firms ("related variety") have a larger propensity to profit from common agglomeration factors in terms of growth or innovation than unrelated firms (Frenken et al. 2007). ${ }^{2}$ The diverse industry mix in an urbanized locality therefore improves the opportunities to interact, copy and modify practices and innovative behavior in the same or related industries. This suggests that it is worthwhile to model intrasectoral and intersectoral dynamics explicitly in a structural adjustment model.

Second, the microeconomic mechanisms underlying agglomeration economies are sectordependent, or even intrasectoral and intersectoral in nature. Duranton and Puga (2004) and Puga (2010) provide state-of-the-art overviews of the exact causes and microfoundations of agglomeration economies. These are: (1) the sharing of facilities in cities, such as local infrastructure; (2) the sharing of suppliers and inputs in larger and more specialized cities,

\footnotetext{
${ }^{2}$ One should note that these economies of variety are often inappropriately labeled "urbanization economies", which are actually externalities that are not related to industry structure but purely to city size. Relatively more populous localities, or places with easier access to metropolitan areas, are also more likely to house universities, industry research laboratories, trade associations and other knowledge-generating institutions.
} 
allowing for vertically integrated activities in clusters, optimizing variety of goods and services and lowering search and transport costs for final goods and intermediates; (3) the sharing of gains of individual specializations and firm indivisibilities, which are especially profitable for professional workers; (4) the sharing of a labor pool, creating a constant market for skills and reducing the risk of unavailable human capital; (5) better matching of buyers and suppliers, skills demanded and offered, and of business partners, reducing transaction costs and trade costs and enhancing cross-sector interactions; and finally (6) learning opportunities for firms and individuals, fueled by knowledge creation, accumulation and diffusion in cities. Especially the last microfoundation of learning causes considerable problems in empirical testing, because little is known about learning behavior of firms in cities.

According to these overviews, many empirical studies have tried to identify the accompanying relevant mechanisms leading to urban externalities. Most of these mechanisms turn out to be sector-specific; many of them are even determined by sectoral composition and intersectoral linkages. For instance, since the seminal Venables (1996) contribution, many studies have identified efficiency effects in vertically linked intermediate products. Intrasectoral and intersectoral linkages are hypothesized and found to be responsible for urban agglomeration economies (Puga 2010). Other studies have focused on the available sectoral varieties in production leading to enhanced growth opportunities (Abdelrahman 1988). Another important literature focuses on regional knowledge spillovers fueled by labor mobility (Almeida and Kogut 1999) and spinoff dynamics (Klepper 2007), arguing that knowledge networks are as mobile as the knowledge carriers (spin-offs, mobile knowledge workers) are. In general, labor mobility and spin-offs are sectorally determined by the demand for specific skills and sector-related market opportunities. Further, a substantial literature points at the importance of informal networking (Lissoni 2001) and research collaboration (Ponds et al. 2010) as moderators of knowledge and information necessary for learning and gaining from localized externalities in cities where these networks have their largest gravitational value. Finally, Storper and Venables (2004) make a strong case for shared labor markets and density advantages of services and infrastructure as important mechanisms fueling agglomeration economies of firms, with a dominant role for sectoral specializations in clusters.

All these identified effects referring to both the sectoral nature of agglomeration effects as well as their underlying microeconomic mechanisms are predominantly concerned with the agglomeration of firms, firm productivity and the associated employment, and most empirical tests in this literature are concerned with the identification of intra-sectoral and inter-sectoral 
productivity and employment dynamics rather than with population dynamics (Glaeser et al. 1992, Henderson et al. 1995). It is remarkable that most studies on population-employment dynamics rule out sectoral linkages, or exogenously introduce (control for) intra-sectoral agglomeration economies (clusters) or inter-sectoral linkages and spillovers. The growing literature on agglomeration externalities hypothesizes that intra-sectoral and inter-sectoral relations of firms are endogenous in models of local and regional economic growth. Different economic sectors inherit and thrive through different external economies that vary in both direction and magnitude (van Oort 2007). This implies that in structural adjustment models inter-sectoral linkages should be determined endogenously, allowing for "jobs to follow jobs" dynamics in addition to "jobs follow people" and "people follow jobs".

\section{Empirics of structural adjustment models}

The "jobs follow jobs" causality is not commonly used in a dynamic population-employment framework. Theoretically, employment growth is considered to be the driving force behind regional economic dynamics. One of the most influential models in urban economics is the monocentric model, which assumes that population growth is endogenously determined by employment growth (Alonso 1964, Muth 1969). The location of housing vis-à-vis the Central Business District (CBD), where employment is concentrated, is a key component of the monocentric model. The larger the distance between residential housing and the CBD, the higher the commuting costs, which capitalizes into relatively lower housing prices and rents. In a microeconomic perspective, new residential properties will be constructed and the city will grow until the housing value equals the cost of producing the property, the alternative value of the land and commuting and transport costs (Brueckner 1978). More recent economic theories, in particular those based on the principles of the New Economic Geography (NEG) similarly assume employment growth to be a pivotal driving force for population movements, however, without assuming population and employment dynamics to be exogenously determined (Fujita et al. 1999).

Real-world deviations from the theoretical monocentric model can create additional constraints as well as opportunities in terms of spatial accessibility. More destinations for travel and more criss-cross relations may occur, but also less congestion in central places (van Oort et al. 2010). Arguably, urban development deviates more and more from the above described theoretical monocentric model. In particular investments in extensive infrastructure networks and concurrent improvements in accessibility have led to edge cities and polycentric urban areas 
in most Western countries. In order to explain these patterns it should be recognized that localized employment growth is not necessarily the only driver of regional economic growth (Boarnet 1994b). In the 1980s, Fujita (1989) already formulated a model based on the bid rent framework initially suggested by Alonso (1964), in which he identified a set of parameters resulting in multiple monocentric as well as polycentric equilibria evolving over time. It is important to note that both household location and firm location are endogenously determined in this model. More recently, Wheaton (2004) introduced a model with mixed land uses and heterogeneous environments to explain the observed stylized facts with respect to urban form and urban function as they are related to population-employment dynamics. He found that especially non-basic sectors that provide commercial services to households seem to be more dependent on population growth than on employment growth in other sectors of the economy. These notions triggered a large empirical literature focusing on the question that is usually succinctly phrased as "do people follow jobs or do jobs follow people?", following the example of Steinnes (1977) who coined the phrase. The relationship between the spatio-temporal dynamics of employment and population and the locations where people (originally) work and live is important, albeit not straightforward to explain.

\section{Urban planning and regional development}

Population-employment dynamics have not formally been recognized as a major policy planning tool in The Netherlands. However, the diminishing spatial accessibility of the locations of consumers, producers and services has been perceived to hamper regional economic growth. Reducing congestion cost and increasing spatial accessibility are therefore among the primary challenges to be dealt with by Dutch policy-makers. The influence of employment and population dynamics, and their relation to urban form and travel patterns, are important determinants of the effectiveness of such regional economic policy in The Netherlands, which is the most densely populated country in Europe. Despite a large tradition of regional and urban economic planning models in The Netherlands, there is little consensus about the incorporation of dynamic relationships between population and employment in these models. This is especially important because regional economic policy is targeted on locally concentrated, spatially clustered housing programs in municipalities outside of the largest core cities in the western and middle part of the country (Structuurvisie 2008).

Although Dutch regional planning policy has always been rather strongly oriented towards 
steering population development, things are gradually changing and one can witness an increase in the interest in regional economic modeling to include population-employment dynamics in policy models for The Netherlands (Thissen 2005). To a large extent this interest is associated with institutional and theoretical developments. Institutionally, the growing formalization and devolution of government policy, especially with respect to infrastructure and urban development investment projects, implied an increased demand for accurate and effective policy planning tools. In particular, the indirect impact of government investment on agglomeration economies is best analyzed in regional economic equilibrium models (Haughwout 2010). New theoretical developments in regional economic modeling, as discussed in Section 2 of this paper, also add to a new and increased scientific interest in applied regional economic models. The dynamics of spatial economic processes are at the heart of these equilibrium models, which makes the models particularly suitable to analyse the effects of changes in the built environment and regional contexts, such as changes in infrastructure, housing, and in urban planning and density (Irwin 2010).

The most recent Dutch policy models are based on the theoretical framework of the New Economic Geography, emphasizing spatial agglomeration effects and market imperfections (Thisse 2010). In order to take these effects into account, markets are not characterized as being perfectly competitive but they are, instead, modeled according to the theory of monopolistic competition. The degree of competition on the different product markets determines the agglomerative strength of the respective sectors, or in other words the degree to which a sector profits from having other firms in its surroundings and hence "jobs follow jobs". Perfect competition only occurs in the extreme case where there are no agglomeration effects. For this type of NEG-inspired computable general equilibrium (CGE) models analytical solutions are not tractable and they have therefore to be solved numerically. Moreover, due to their highly non-linear nature these types of models are generally even difficult to solve numerically. Most NEG models used in policy analysis are therefore based on simplifications of the theoretical models in order to make the models analytically tractable (see Baldwin et al. 2003, for an overview). As relevant local and regional economic processes differ according to the level of spatial aggregation, different CGE models are typically needed to address different spatial problems in order to avoid the problem of "ecological fallacy". These models typically also differ in the way in which the effects of nationwide economic growth on different regions (distributive effects) and the effects of regional economic growth on the national economy (generative effects) are taken into account. In many existing policy models the importance of spatially determined externalities to explain regional 
growth differences is emphasized, even although there is not one single theoretical modeling framework available that encompasses the spatial externality aspect completely. Thissen et al. (2005) therefore conclude that alternative modeling approaches are needed in addition to the theoretically superior New Economic Geography approach, because such alternative CGE models exhibit specific properties regarding, for example, the quality of labor, the spatial resolution, and the extent to which spatial mobility is accounted for, that would be very difficult to incorporate in a NEG-based policy modeling approach.

These alternative modeling approaches are also needed to explain how governments may use specific spatial interactions to stimulate economic growth or counteract adverse economic policy effects. Virtually all economic policy measures, directly or indirectly, affect the country's regional economic growth and income distribution. This in turn, may trigger migration and lead to even stronger changes in the spatial economic landscape. The economic landscape of a country can be viewed as the time and costs necessary to connect two points in space for economic purposes, including trade and commuting. Policy measures that affect the economic landscape can be physical measures such as transport infrastructure, housing and the facilitation of industry, but also spatially non-neutral instruments such as taxes or subsidies, including road pricing (Bolton 1992, Barca et al. 2011). Housing policy provides opportunities for consumption and labor to be utilized at a certain location, while the development of industrial areas enables economic actors to use labor and attract firms to a specific location in space. Extensions of cost-benefit models that incorporate and value housing and firm location externalities are therefore desirable to account for these spillovers in spatial policy interventions (de Vor and de Groot 2010).

This paper offers such an extension, by analyzing population-employment dynamics and the associated spatial externalities in a spatial econometric modeling framework that forecasts structural adjustments in population and employment growth for a policy proposal to built additional housing capacity in the city of Almere in The Netherlands.

\section{Sectoral dynamics in population-employment models}

The policy model we develop in this section comprises a system of equations for population and sectoral employment growth. The spatial level of aggregation we use is the municipality level in The Netherlands. Municipalities are administrative spatial units consisting of one or more cities, usually in a contiguous area. Many urban economic or economic geography studies typically use larger administrative spatial units when measuring agglomeration effects. Duranton 
and Overman (2005) argue that many measures of concentration use arbitrary large spatial units, which may be problematic as it may lead to severe biases. First, spatial units are often very different in size and are therefore not comparable. A solution is to use relative indices such as location quotients, but these measures are generally not informative when it comes to the absolute concentration of an industry or the population. Second, spatial units are treated symmetrically, so firms in neighboring regions are treated in exactly the same way as a firm that is located further away. This may lead to distortive spatial sorting effects (Briant et al. 2010). In order to circumvent these problems we use data with a relatively high spatial resolution, although this obviously makes it desirable to account for the potentially distorting effects of spatial autocorrelation.

The literature review and the meta-analysis conclusions described above indicate that the nature of the relation between employment and population changes is primarily an empirical issue. The resulting outcome of the empirical analysis depends, among other things, on the time period, the spatial scale, and the sectoral and population decomposition that is chosen. We therefore construct a model that is as flexible as possible, along the lines of Steinnes (1977), Carlino and Mills (1987) and Boarnet (1994a).

In our empirical application, we assume the population to be homogeneous, ${ }^{3}$ but we allow employment to be heterogeneous across $S$ industries or sectors. We further assume that the following system of equations holds in equilibrium:

$$
\begin{aligned}
p_{t}^{*} & =f\left(\mathbf{X}_{t}^{p}, \bar{e}_{t}^{1, *}, \ldots, \bar{e}_{t}^{S, *}\right) \\
e_{t}^{1, *} & =g_{1}\left(\mathbf{X}_{t}^{e^{1}}, \bar{p}_{t}^{*}, \bar{e}_{t}^{2, *}, \ldots, \bar{e}_{t}^{S, *}\right) \\
& \vdots \\
e_{t}^{S, *} & =g_{S}\left(\mathbf{X}_{t}^{e^{S}}, \bar{p}_{t}^{*}, \bar{e}_{t}^{1, *}, \ldots, \bar{e}_{t}^{S-1, *}\right),
\end{aligned}
$$

where $p_{t}$ is a vector of regional population shares at time $t,{ }^{4} e_{t}^{s}$ is a vector of regional sectoral employment shares in sector $s \in(1, \ldots, S)$ at time $t, f$ and $g_{s}$ are functional relationships, and $\mathbf{X}$ is a matrix of equation-specific exogenous variables explaining regional population and regional

\footnotetext{
${ }^{3}$ Ideally, one would maybe like to decompose the population according to age cohorts or education levels, but due to limited data availability and in order to limit the numerical complexity of the model we refrain from doing so in the empirical application. In a theoretical sense this extension is, however, rather straightforward.

${ }^{4}$ In the main text we omit the subscript $r$ to avoid cluttering the notation. However, all shares are defined as regional shares. So, the share of the population in region $r$ is defined as $p_{r}=P_{r} / \sum_{r=1}^{R} P_{r}=P_{r} / P$, where $P_{r}$ denotes the regional population and $P$ the total (national) population across all regions $r \in(1, \ldots, R)$. Sectoral employment shares are defined analogously. All regional shares are defined for a specific time $t$.
} 
sectoral employment shares. The overbar signals that a variable pertains to a "local" labor market that potentially extends beyond the region itself, and the asterisk reveals an equilibrium value.

The (logarithm) of the growth rates of the regional population and regional employment shares are assumed to follow a loglinear adjustment model:

$$
\begin{aligned}
\Delta \log p_{t} & =\log p_{t}-\log p_{t-1}=\lambda_{p}\left(\log p_{t}^{*}-\log p_{t-1}\right) \\
\Delta \log e_{t}^{1} & =\log e_{t}^{1}-\log e_{t-1}^{1}=\lambda_{e^{1}}\left(\log e_{t}^{1, *}-\log e_{t-1}^{1}\right) \\
& \vdots \\
\Delta \log e_{t}^{S} & =\log e_{t}^{S}-\log e_{t-1}^{S}=\lambda_{e^{S}}\left(\log e_{t}^{S, *}-\log e_{t-1}^{S}\right),
\end{aligned}
$$

where $\Delta$ denotes the log difference operator. ${ }^{5}$

Assuming a linear specification and combining both the system specified in equation (1) and the set of assumptions of equation (2) yields:

$$
\begin{aligned}
\Delta \log p_{t}= & \mathbf{X}_{t}^{p} \beta_{p}+\sum_{s=1}^{S} \frac{\alpha_{p}^{s}}{\lambda_{e^{s}}} \Delta \log \bar{e}_{t}^{s}+\sum_{s=1}^{S} \alpha_{p}^{s} \log \bar{e}_{t-1}^{s}-\lambda_{p} \log p_{t-1} \\
\Delta \log e_{t}^{1}= & \mathbf{X}_{t}^{e^{1}} \beta_{e^{1}}+\frac{\alpha_{e^{1}}^{p}}{\lambda_{p}} \Delta \log \bar{p}_{t}+\alpha_{e^{1}}^{p} \log \bar{p}_{t-1}+ \\
& \sum_{s=2}^{S} \frac{\alpha_{e^{1}}^{s}}{\lambda_{e^{s}}} \Delta \log \bar{e}_{t}^{s}+\sum_{s=2}^{S} \alpha_{e^{1}}^{s} \log \bar{e}_{t-1}^{s}-\lambda_{e^{1}} \log e_{t-1}^{1}, \\
\vdots & \\
\Delta \log e_{t}^{S}= & \mathbf{X}_{t}^{e^{S}} \beta_{e^{S}}+\frac{\alpha_{e^{S}}^{p}}{\lambda_{p}} \Delta \log \bar{p}_{t}+\alpha_{e^{S}}^{p} \log \bar{p}_{t-1}+ \\
& \sum_{s=1}^{S-1} \frac{\alpha_{e^{S}}^{s}}{\lambda_{e^{s}}} \Delta \log \bar{e}_{t}^{s}+\sum_{s=1}^{S-1} \alpha_{e^{S}}^{s} \log \bar{e}_{t-1}^{s}-\lambda_{e^{S}} \log e_{t-1}^{S},
\end{aligned}
$$

where $\beta$ are parameters measuring the impact of exogenous conditioning factors specified in $\mathbf{X}$, and $\alpha$ and $\lambda$ are parameters associated with the endogenously determined changes in the levels and growth rates of the regional population and employment shares. The $\lambda$ parameters can be

\footnotetext{
${ }^{5}$ The loglinear specification in shares differs from the original Boarnet (1994a) model, but this specification is attractive: $\Delta \log p_{t}$ constitutes the logarithm of the growth rate of the regional population shares, which is equivalent to the logarithm of the growth rate of the regional population minus the logarithm of the growth rate of the national population. Mathematically, $\Delta \log p_{t}=\log \left(P_{r t} / P_{r t-1}\right)-\log \left(P_{t} / P_{t-1}\right)$, which shows that the spatial distribution of the logarithm of the regional growth rate of the population shares is only uniformly affected by the national population growth rate. This is an attractive property for the policy simulations reported in the next section, because the growth rate of the regional population shares is driven by the endogenously determined growth rate of the regional population corrected for the spatially uniform impact of an exogenously determined national population growth.
} 
interpreted as partial adjustments to a long-run equilibrium, as long as their absolute values are smaller than unity in order for the responses to be stationary.

In order to implement the system in equation (3) we deviate from the traditional literature again and specify that the impact of the local labor market can be modeled by a spatial autoregressive process using $\rho_{p} \mathbf{W} \Delta \log p_{t}$ for the impact on population changes and $\rho_{e^{s}} \mathbf{W} \Delta \log e_{t}^{s}$ for the impact on employment changes in sector $s$ (following a suggestion in Hoogstra et al. 2011). ${ }^{6}$ The spatial weights matrix $\mathbf{W}$ determines the spatial range of the local labor market (including the associated population) by identifying the neighboring regions that belong to the same labor market. It is common practice to row-standardize the spatial weights matrix, so that all row-sums are equal to unity.

The dynamics between population and employment shares for each region $r$ in a local labor market are now subject to two types of feedbacks, the system feedback between and among the various forms of employment and the population as well as spatial feedbacks and spillovers modeled through the spatial autoregressive process. Using a more concise notation, this leads to the following empirical specification:

$$
\begin{aligned}
\Delta p_{t} & =\rho_{p} \mathbf{W} \Delta p_{t}+\mathbf{X}_{t}^{p} \beta_{p}+\sum_{s=1}^{S} \gamma_{p}^{s} \Delta e_{t}^{s}+\sum_{s=1}^{S} \alpha_{p}^{s} e_{t-1}^{s}-\lambda_{p} p_{t-1}+u_{t}^{p} \\
\Delta e_{t}^{1} & =\rho_{e^{1}} \mathbf{W} \Delta e_{t}^{1}+\mathbf{X}_{t}^{e^{1}} \beta_{e^{1}}+\gamma_{e^{1}}^{p} \Delta p_{t}+\alpha_{e^{1}}^{p} p_{t-1}+\sum_{s=2}^{S} \gamma_{e^{1}}^{s} \Delta e_{t}^{s}+\sum_{s=2}^{S} \alpha_{e^{1}}^{s} e_{t-1}^{s}-\lambda_{e^{1}} e_{t-1}^{1}+u_{t}^{e^{1}} \\
& \vdots \\
\Delta e_{t}^{S} & =\rho_{e^{S}} \mathbf{W} \Delta e_{t}^{S}+\mathbf{X}_{t}^{e^{S}} \beta_{e^{S}}+\gamma_{e^{S}}^{p} \Delta p_{t}+\alpha_{e^{S}}^{p} p_{t-1}+\sum_{s=1}^{S-1} \gamma_{e^{S}}^{s} \Delta e_{t}^{s}+\sum_{s=1}^{S-1} \alpha_{e^{S}}^{s} e_{t-1}^{s}-\lambda_{e^{S}} e_{t-1}^{S}+u_{t}^{e^{S}},
\end{aligned}
$$

where the logarithm operator has been left out, and the $\gamma$ coefficients replace the $(\alpha / \lambda)$ parameters of equation (3). Obviously, the equations in (4) form a simultaneous equations system due to the endogenous log difference variables on the right-hand side.

\footnotetext{
${ }^{6}$ Although similar in nature to the specification in Boarnet (1994b), this specification avoids the use of a $(\mathbf{I}+\mathbf{W})$ matrix. The problem with the latter is that with a row-standardized weights matrix the region itself and the sum of all its neighbors are, rather arbitrarily, given equal weight and there is no distance decay implied by the specification. One should also note that this specification is "richer" and more flexible than the original $(\mathbf{I}+\mathbf{W})$-approach. By incorporating an autoregressive process in the dependent variable the spatial correlation is implicitly extended to all exogenous variables, but in this case allowing for distance decay.
} 


\section{Data and estimation results}

In this section we implement the system in (4) using the (logarithm) of the growth rates of the regional population and regional employment shares in The Netherlands during the period 1996-2008 as the dependent variables. We start by describing the data in subsection 6.1, and subsequently present the estimation results in subsection 6.2. Because of the endogeneity and spatial interaction in the system of equations in (4) the estimation results are not directly interpretable in terms of marginal effects. The last subsection therefore describes how the marginal effects can be calculated from the parameter estimates.

\subsection{Data}

We estimate the model with Dutch panel data from 1996 to 2008 . We use all 443 municipalities in The Netherlands as our spatial unit of analysis. Dutch municipalities are usually smaller than local labor markets, but they are typically large enough to capture most urban forces of attraction for both firms and households. The employment data are taken from the so-called LISA database, the "National Information System for Employment" (see http://www.lisa.nl/). This database is collected by 18 (regional) organizations and the main aim of the survey is to provide an accurate representation of the employment structure in Dutch industries. Data are collected through an annual questionnaire among the population of all economic actors, including the government, education and research establishments, healthcare institutions and professionals.

Table 1 shows how the originally 49 two-digit industries in The Netherlands have been aggregated into seven composite production sectors. These seven sectors are chosen in such a way that the sector classification mimics the classification that has been utilized in other Dutch studies of population-employment models, such as TigrisXL. Our aggregate classification comprises Agriculture (A), the large heterogeneous sector Industry (I), the distribution sector $(\mathrm{D})$, the retail sector $(\mathrm{R})$, remaining consumer services $(\mathrm{C})$, producer services including the financial sector $(\mathrm{P})$, and the government sector including health care and education $(\mathrm{G})$.

In addition to changes in the levels and growth rates of the regional population and employment shares, as given in equation (4), we have modeled other attraction factors for firms at the level of municipalities. Typically, these factors are concerned with accessibility characteristics, land prices and land use restrictions, and regional economic conditions. In order to capture these factors we include the size of the municipality, which accounts for density effects as well, and in line with Boarnet et al. (2005), the percentage of specific land uses within that municipality, 
Table 1: Two-digit employment data for 49 industries and aggregation into seven sectors

\begin{tabular}{|c|c|c|c|c|c|}
\hline Id & Industry & Sector & Id & Industry & Sector \\
\hline 01 & Agriculture and fishery & $\mathrm{A}$ & 40 & Electricity and water supply & I \\
\hline 11 & Natural resources & $\mathrm{A}$ & 45 & Building and construction & I \\
\hline 15 & Food and beverage industry & I & 51 & Wholesale trade & $\mathrm{C}$ \\
\hline 16 & Tobacco industry & I & 52 & Retail & $\mathrm{R}$ \\
\hline 17 & Textile industry & I & 55 & Hotels, restaurants and bars & $\mathrm{C}$ \\
\hline 18 & Clothing industry & I & 60 & Distribution over land & $\mathrm{D}$ \\
\hline 19 & Leather goods industry & I & 61 & Distribution over water & $\mathrm{D}$ \\
\hline 20 & Timber industry & I & 62 & Distribution by air & $\mathrm{D}$ \\
\hline 21 & Paper industry & I & 63 & Distribution services & $\mathrm{D}$ \\
\hline 22 & Publishing and reproduction & I & 64 & Telecommunication and post & $\mathrm{P}$ \\
\hline 23 & Oil processing industry & I & 65 & Banks & $\mathrm{P}$ \\
\hline 24 & Chemical industry & I & 66 & Financial services & $\mathrm{P}$ \\
\hline 25 & Synthetic and rubber industry & I & 70 & Real estate intermediates & $\mathrm{C}$ \\
\hline 26 & Glass and ceramic industry & I & 71 & Movable est. intermed. & $\mathrm{C}$ \\
\hline 27 & Primary metal industry & I & 72 & Computer-services & $\mathrm{P}$ \\
\hline 28 & Metal production industry & I & 73 & Research and development & $\mathrm{P}$ \\
\hline 29 & Machinery industry & I & 74 & Other business services & $\mathrm{P}$ \\
\hline 30 & Computer industry & I & 75 & Government & G \\
\hline 31 & Electronics industry & I & 80 & Education & G \\
\hline 32 & Audio and telecom. industry & I & 85 & Health care & G \\
\hline 33 & Medical instruments industry & I & 90 & Environmental services & $\mathrm{G}$ \\
\hline 34 & Car industry & I & 91 & Unions & G \\
\hline 35 & Transport industry (excl. cars) & I & 92 & Culture, sports and recreation & G \\
\hline 36 & Furniture industry & I & 93 & Personal services & G \\
\hline 37 & Recycling industry & I & & & \\
\hline
\end{tabular}

which may also be seen as a prerequisite for the industrial sector. In order to correct for potentially rationed location space for firms we include the municipality's growth in industrial parks.

Population data are taken from the so-called "CBS Bevolkingsstatistiek", which are derived from the population registries of the municipalities. As the main variable of interest, we chose the size of the labor force, defined as the population between 15 and 65 years of age. To measure the attractiveness of a municipality for households we have incorporated the following conditioning variables: the size of the municipality (in hectares) to account for population density differences, the percentage of land used for built area, nature, agriculture, water, recreation, et cetera, and the age structure of the population within a municipality operationalized as the percentage of the population that is younger than 25 , or older than 65 years of age.

Figure 1 shows the annual population and employment growth rate for Dutch municipalities between 1996 and 2008. It is easy to verify that employment has been growing faster than the population in most municipalities, except for the peripheral municipalities in the northeast and 


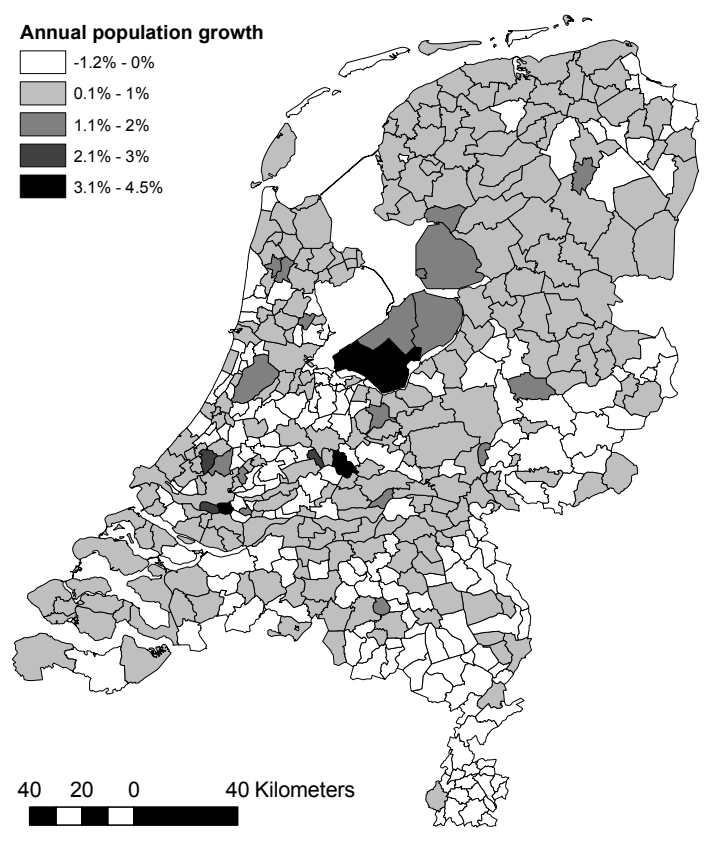

(a)

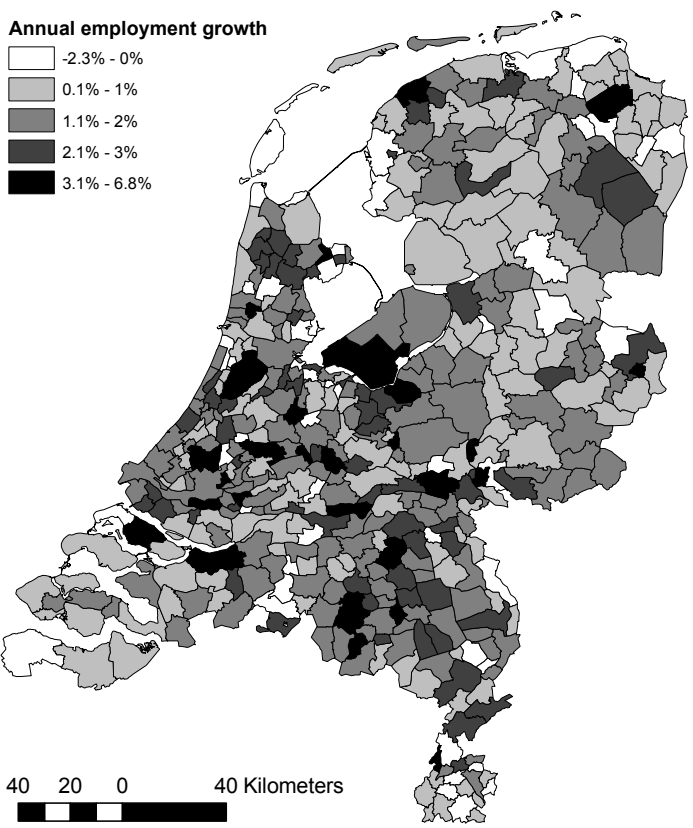

(b)

Figure 1: Annual growth rate of the population (aged 15-65 years) and (total) employment in percentages, for municipalities in The Netherlands, 1996-2008

the southwest. Population growth is clearly concentrated in the city of Almere, located in the polder in the middle of the country. Depopulation has been prevalent in the southeast and the eastern part of the country. Vermeulen and van Ommeren (2007) showed that population growth in The Netherlands is to a large extent driven by housing supply, and in Vermeulen and Rouwendal (2007) they found that the price elasticity of housing supply is almost zero, especially in the short run. It is therefore appropriate to assume that, at least for The Netherlands, housing supply is exogenous to population growth, and we therefore incorporate changes in the housing stock as an exogenous variable in our population growth model. The spatial distribution of the annual employment growth rate is much more scattered throughout the country, although it does show that the Amsterdam-Almere conurbation has been experiencing relatively high growth rates.

Table 2 provides the descriptive statistics for both the employment and the population variables as well as the other conditioning variables used in our econometric model. On average, the government, healthcare and education sector is the largest employment sector in The Netherlands, followed by industry and producer services; the agricultural sector is clearly the smallest in terms of employment. In addition, it seems that the variation in the sectoral employment structure of municipalities is quite large, which is indicative of spatial clustering of 
specific sectors. On average, Dutch municipalities have a labor force of about 25,000 potential laborers, with the largest municipality (Amsterdam) having about 550,000 members of the labor force. The land use variables show that buildup and semi-buildup areas only constitute about 14 percent of the entire land area, and nature and recreation areas occupying approximately the same area. Most of the land in The Netherlands (56 percent) is still used for agriculture.

Table 2: Descriptive statistics for municipalities in The Netherlands, $1996-2008(N=5759)$

\begin{tabular}{|c|c|c|c|c|}
\hline Variable & Minimum & Mean & Maximum & St. dev. \\
\hline \multicolumn{5}{|l|}{ Employment } \\
\hline Agriculture & 0 & 571 & 14,091 & 801 \\
\hline Industry & 4 & 3,469 & 53,435 & 4,959 \\
\hline Logistics and transport & 8 & 1,929 & 62,165 & 4,674 \\
\hline Retail sector & 3 & 1,528 & 37,140 & 2,629 \\
\hline Other consumer services & 60 & 1,894 & 83,823 & 4,926 \\
\hline Producer services & 18 & 2,801 & 169,890 & 9,427 \\
\hline Government, healthcare, education & 48 & 4,149 & 129,220 & 10,447 \\
\hline Population (15-65 years) & 609 & 24,502 & 541,470 & 40,106 \\
\hline Size (hectares) & 178 & 7,291 & 46,781 & 6,911 \\
\hline Population < 24 year $(\%)$ & 0 & 28 & 52 & 8.6 \\
\hline Population > 65 year $(\%)$ & 0 & 13 & 28 & 4.5 \\
\hline$\Delta$ Housing supply & -653 & 134.1 & 5,794 & 284.9 \\
\hline$\Delta$ Industrial sites (hectares) & -39 & 2.3 & 96 & 5.3 \\
\hline \multicolumn{5}{|l|}{ Land use variables (in percentages) } \\
\hline Surface water & 0 & 4.1 & 37.3 & 5.0 \\
\hline Agriculture & 0 & 56.3 & 94.7 & 26.9 \\
\hline Natural areas and recreation & 0 & 14.6 & 96.5 & 15.0 \\
\hline Semi-buildup areas & 0 & 1.4 & 17.4 & 1.9 \\
\hline Buildup areas & 0 & 12.5 & 67.6 & 13.0 \\
\hline Transport infrastructure & 0 & 3.4 & 12.8 & 1.9 \\
\hline
\end{tabular}

\subsection{Estimation results and marginal effects}

In order to estimate the system of equations given in (4), we first stack all time periods in our dataset in order to arrive at vectors of size $N T \times 1$. This allows us to write the spatial simultaneous equations system in matrix notation as (Kelejian and Prucha 2004): ${ }^{7}$

$$
\mathbf{Y}=\overline{\mathbf{Y}} \Gamma+\mathbf{X} B+\mathbf{U}
$$

\footnotetext{
${ }^{7}$ For convenience and consistent notation, we denote all explanatory variables with $\mathbf{X}$. This implies that $\mathbf{X}$ now also includes the spatially and temporally lagged population and employment variables. Furthermore, we note that the logarithm operator has been omitted for notational convenience.
} 
where $\mathbf{Y}=\left(\Delta p, \Delta e^{1}, \ldots, \Delta e^{S}\right)^{\prime}, \mathbf{X}=\left(\mathbf{X}^{p}, \mathbf{X}^{e^{1}}, \ldots, \mathbf{X}^{e^{S}}\right)^{\prime}, \mathbf{U}=\left(\mathbf{u}^{p}, \mathbf{u}^{e^{1}}, \ldots, \mathbf{u}^{e^{S}}\right)^{\prime}$, and $\overline{\mathbf{Y}}=$ $\left(\mathbf{V} \Delta p, \mathbf{V} \Delta e^{1}, \ldots, \mathbf{V} \Delta e^{S}\right)^{\prime} .{ }^{8}$ Because the time periods are stacked, the spatial weight matrix $\mathbf{V}$ is an $N T \times N T$ block-diagonal matrix with an $N \times N$ spatial weight matrix $\mathbf{W}$ on the diagonal for every time period $t$. Clearly, there are several endogeneities at work in this pooled system of equations: the system feedbacks between regional population growth rates and regional sectoral growth rates, the system feedbacks among the regional sectoral growth rates, and the spatial spillovers and feedbacks modeled through the spatially autoregressive endogenous variables. Our estimation procedure should take this into account.

We implement $\mathbf{W}$ as a row-standardized first-order queen contiguity matrix and estimation of (4) is performed utilizing the generalized spatial three-stage least squares (3SLS) estimator as described in Kelejian and Prucha (1998) and Kelejian and Prucha (2004). Following customary practice, the instruments we use are the exogenous variables and their spatially lagged versions. In order to allow for spatial heterogeneity across regions we incorporate regional fixed effects at the so-called COROP-level. COROP regions are smaller than Dutch provinces, but larger than municipalities. On average, each COROP-region consists of 11 municipalities.

A large number of the coefficients in Table 3 are (marginally) statistically significant. Both the coefficients and their associated standard errors should, however, not be taken at face value because due to the presence of the spatially lagged endogenous variables the coefficients are not marginal effects. With this in mind, we nevertheless note that changes in housing supply seem to affect population, but changes in the availability of industrial sites only seems to influence industrial employment. All $\lambda$ coefficients are negative as theory suggests, except for population growth, which in this period was very heavily concentrated in the Amsterdam-Almere conurbation (see Figure 1).

Marginal effects can be easily derived by writing the system of equations in (4) in reduced form. Ignoring the time dimension for notational convenience, we can write (4) for a specific year in compact form as:

$$
\mathbf{Y}=(\mathbf{I}-\mathbf{\Xi})^{-1}(\mathbf{X} B+\mathbf{U})
$$

where $\mathbf{I}$ is the identity matrix, $\boldsymbol{\Xi}$ is a matrix composed with the weight matrix and the $\Lambda$ and $\Gamma$ parameters, and the remaining variables are as defined previously. Because the expectation of the errors are zero, predicted changes in the (logarithm of the) growth rates of the regional

\footnotetext{
${ }^{8}$ In addition to the system concisely given in (4) we also allow the error vectors to be spatially correlated; so, $\mathbf{u}=\varphi \mathbf{W u}+\mu$, where the latter is an independently and identically distributed error. This is not made explicit in the main text, because it is a nuisance process.
} 
population and employment shares can be written as:

$$
\hat{\mathbf{Y}}=(\mathbf{I}-\hat{\boldsymbol{\Xi}})^{-1} \mathbf{X} \hat{B},
$$

where $\hat{\boldsymbol{\Xi}}$ and $\hat{B}$ are matrices of estimated coefficients. The matrices $\hat{\boldsymbol{\Xi}}, \mathbf{X}$ and $\hat{B}$ can be derived as:

$$
\begin{gathered}
\hat{\boldsymbol{\Xi}}=\left[\begin{array}{cccc}
\hat{\rho}_{11} \mathbf{W} & \hat{\gamma}_{12} \mathbf{I} & \cdots & \hat{\gamma}_{1 S} \mathbf{I} \\
\hat{\gamma}_{21} \mathbf{I} & \hat{\rho}_{22} \mathbf{W} & \cdots & \hat{\gamma}_{2 S} \mathbf{I} \\
\vdots & & & \\
\hat{\gamma}_{S 1} \mathbf{I} & \hat{\gamma}_{S 2} \mathbf{I} & \cdots & \rho_{S S} \mathbf{W}
\end{array}\right] \\
\mathbf{X}=\left[\begin{array}{llllll}
\mathbf{X}_{1} & \mathbf{y}_{2, t-1} & \mathbf{y}_{3, t-1} & \cdots & \mathbf{y}_{S, t-1} & \mathbf{y}_{1, t-1} \\
\mathbf{X}_{2} & \mathbf{y}_{1, t-1} & \mathbf{y}_{3, t-1} & \cdots & \mathbf{y}_{S, t-1} & \mathbf{y}_{2, t-1} \\
\mathbf{X}_{S} & \mathbf{y}_{1, t-1} & \mathbf{y}_{2, t-1} & \cdots & \mathbf{y}_{S-1, t-1} & \mathbf{y}_{S, t-1}
\end{array}\right],
\end{gathered}
$$

and

$$
\hat{B}=\left[\begin{array}{cccccc}
\hat{\beta}_{1} & \hat{\alpha}_{12} & \hat{\alpha}_{22} & \cdots & \hat{\alpha}_{1 S} & \hat{\lambda}_{1} \\
\hat{\beta}_{2} & \hat{\alpha}_{21} & \hat{\alpha}_{23} & \cdots & \hat{\alpha}_{2 S} & \hat{\lambda}_{2} \\
& & & & & \\
\hat{\beta}_{2} & \hat{\alpha}_{S 1} & \hat{\alpha}_{S 2} & \cdots & \hat{\alpha}_{S S-1} & \hat{\lambda}_{S}
\end{array}\right]
$$

where $S$ now denotes the total number of equations, including the population equation. The estimation of the system of equations in (4) and subsequent substitution of the estimated parameters in (6) allows us to calculate the predicted impacts on the (logarithm) of the growth rates of the regional population and sectoral employment shares of an exogenous policy shock. In the next section we calculate the estimated marginal effects for a proposed housing project in the city of Almere.

\subsection{A simulation experiment for the city of Almere}

In the coming decades there is a large need for new dwellings in the western part of The Netherlands, especially in the so-called North-wing of the Randstad, comprising the region with the cities of Amsterdam and Utrecht (Amsterdambrief 2011). Land available for construction is scarce in this part of The Netherlands, which has led to an upward pressure on housing prices that may in the future perhaps act as an impediment for regional economic growth (de Groot 
et al. 2010). The only region that still has a relative abundance of land is the province of Flevoland, which consists of land reclaimed during the 1950s and 60s from the former sea called "Zuiderzee" (in Dutch). The largest town in the Flevopolder is the city of Almere, which is situated in the western part of this region, just east of Amsterdam.

At the moment, Almere is a middle-sized new town with a population of 190,000 , but it is projected to become the fifth largest town in The Netherlands in 20 years time. By then, the city is expected to have 350,000 additional inhabitants, and an additional 100,000 newly created jobs. In order to accommodate future growth of the city of Almere, the government is planning to build 60,000 new dwellings, accompanied by significant improvements in public transportation infrastructure between Schiphol Airport, Amsterdam and Almere. Ultimately, the project should transform the city of Almere from a dormitory suburban town of Amsterdam to a vibrant, dynamic and entrepreneurial city with endogenous economic growth potential (Berg et al. 2007). ${ }^{9}$

In the design of this project it has implicitly been assumed that population growth will automatically lead to job growth, and that scaling up in population will eventually create 100,000 additional jobs (CPB 2009). The latter is considered important because at the moment there is a large spatial mismatch between the number of jobs and workers available in the city of Almere, which causes severe traffic congestion, especially on the highway west of Almere that, via a large bridge, leads to Amsterdam (Amsterdambrief 2011).

Because of the sheer size of the project, several ex ante scenario analyses have been performed. These scenario analyses typically assume population to be exogenous to employment. In order to determine what removing the implicit "jobs follow people" assumption implies for the employment projections for the city of Almere and its surroundings, we carry out a simulation experiment using the previously described system of equations allowing for heterogeneous endogenous sectoral employment effects. In the policy scenario we keep all non-employment and non-population variables constant, except for the change in housing stock, which is projected to increase by 3,000 per year over a period of 20 years. In the base scenario, none of the exogenous variables changes, but the population-employment dynamics result in a different spatial distribution of the population and sectoral employment in 2028, because the situation in 2008 does not constitute an equilibrium. The simulations are calibrated on the observed regional population and employment shares in 2008.

\footnotetext{
${ }^{9}$ As pointed out by one of the reviewers, instead of population growth the case of a declining regional population becomes increasingly more relevant nowadays. Our modeling setup can be applied for that case as well.
} 


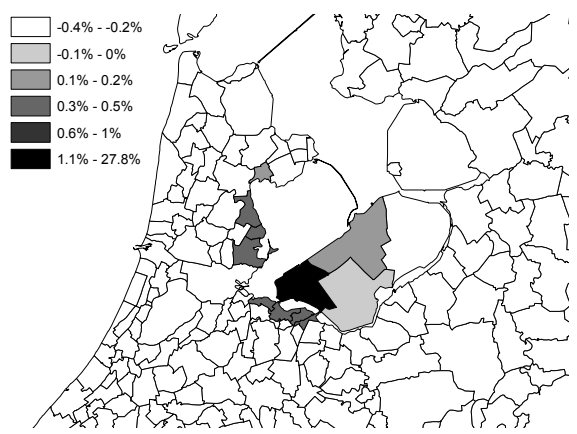

(a)

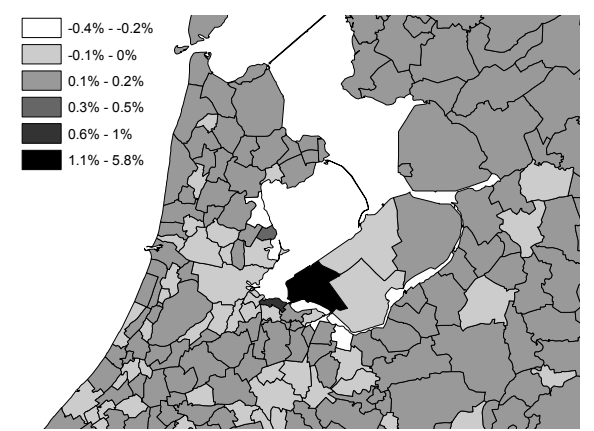

(b)

Figure 2: Percentage point difference in population (a) and employment size (b) between the base scenario and the policy scenario (60,000 additional dwellings in Almere over a period of 20 years) in 2028

We do not report the simulation results as absolute population and employment numbers, because that would require us to make assumptions about the national changes in the size of the population and (sectoral) employment as well as about potential future changes in average household occupancy rates. Rather than reporting absolute outcomes of our scenarios we will focus on the percentage point difference in population size and employment size in 2028 of the policy scenario as compared to the base scenario (i.e., without any exogenous impulse). It is not feasible to decompose the total impacts into those resulting from backward and forward linkages. The setup of our model is, however, such that we allow backward linkages between different sectors and the population to play out as well as location and urbanization externalities to impact population and employment dynamics. The latter effects are taken into account through the spatially and temporally lagged endogenous employment variables in the employment equations.

Figure 2 shows the obvious additional increase in population for the city of Almere with smaller spillover effects to adjacent municipalities under the policy scenario as compared to the base scenario, and it also shows that the population influx largely comes equally from all remaining Dutch municipalities. ${ }^{10}$ In contrast to the positive population influx associated with the building of extra dwellings, employment in the city of Almere grows as well, although at a lesser rate, but the influx of workers seems to draw heavily from adjacent municipalities. Hence, employment growth does not seem to carry over to the surrounding municipalities. The relative magnitude of the population and employment effects shows that the "jobs follow people" maxim does not seem to be fully appropriate at a local scale. It only holds to a certain extent at a somewhat wider geographical scale.

\footnotetext{
${ }^{10}$ Note that we do not explicitly allow for generative growth, which may occur in addition to the distributive effects of the policy change.
} 
It is difficult to assess on the basis of the results of Table 3 whether "people follow jobs", "jobs follow people" or "jobs follow jobs". However, a detailed look at the magnitude of the estimated $\gamma$-coefficients shows that population is largely exogenous in this model; it is not driven by employment changes. We rather observe that especially in the retail and government, education and health case sectors "jobs follow people", and in industry as well as in all other sectors sectoral employment is the driving force, and the maxim "jobs follow jobs" applies. Figure 3 gives a more detailed, and more accurate perspective since it is based on the estimated marginal effects. The figure shows the percentage differences between the policy scenario and the base scenario for each of the employment sectors. Clearly, employment in the various sectors reacts rather differently to the construction of new dwellings and the associated surge in the city's population. The restricted policy impact on the employment in the city of Almere shown in Figure (2b) is primarily caused by the fact that employment growth in agriculture (3a), industry (3f), logistics (3c) and consumer services (3e) materializes outside of the city of Almere rather than within the city limits. Arguably, the policy impacts on retail employment (3d), government, education and healthcare (3g) and employment in producer services (3f) are positively affected by the population influx.

Overall, these results imply that the spatial distribution of the impacts of backward linkages and agglomeration externalities vary substantially by sector, and they seem to affect employment growth at rather different spatial scales. It is obvious that the simple maxim "people follow jobs" does not apply. Instead, our results show that in particular for industry and retail "jobs follow people". For other sectors, in particular the relatively footloose producer and consumer services, the number of jobs is not driven by population surges but rather by intersectoral dynamics ("jobs follow jobs"), which materialize in a wider geographical area. Overall, the dynamics of the population seem to be largely exogenous to the model.

\section{Conclusion}

This main focus of this paper was to explicitly model sectoral variation in a dynamic adjustment, or population-employment interaction, model. We showed that it is relatively straightforward to model sectoral dynamics within a Carlino-Mills type model and that such a distinction is relevant. Our estimation results suggest that population is exogenous to employment, population changes drive employment in particular in the retail, producer services and government, education and health sectors, and employment in all sectors depends strongly on intersectoral dynamics. 
This latter finding is new to dynamic adjustment modeling. In general, as regional-economic theory would predict, employment in non-basic sectors follows population changes more closely than employment in basic sectors. However, one should note that in our analysis utilizing the geographical scale of municipalities and seven different sectors, the distinction between basic and non-basic sectors of the economy may become somewhat counterintuitive. For instance, consumer services seems to behave more as a basic than as a non-basic sector. This is partly due to the fact that this sector does not comprise retail, and therefore mainly consists of firms that are prone to agglomeration externalities in consumption, such as hotels, restaurants and bars.

A major concern in dynamic adjustment models is their stability when used as a forecasting or scenario-analysis model. The empirical results of our model show that it is intrinsically stable or stationary. This is partly due to the loglinear specification of regional changes in population and employment shares. A specification using absolute levels or changes is generally much less stable. There is therefore always a trade-off between a higher level of realism and a better tractability of a model. Especially when using scenario-analyses, more gains can probably be accrued from constructing more realistic scenarios than from more realistic, and hence more detailed, underlying models. Nevertheless, these underlying structural models are of crucial importance in discovering the relevant endogenous structure of the dynamics between employment and population. In the case of The Netherlands, we find rather strong evidence that population changes are largely exogenous to employment changes, and not the other way around as previously identified by Vermeulen and van Ommeren (2007). Equally important, at least at the municipality level, is the finding that intersectoral dynamics are important drivers of regional sectoral employment changes, that they are more important than population changes, and that their effect shows up even within the Dutch institutional context of strict regulatory housing and planning restrictions. This is a particularly useful finding because it can inform local policy-making. Instead of focusing on increasing the size of the city per se, it seems much more effective to design carefully tailored and targeted local and regional industry policies in order to maximize the extent to which backward linkages and spatial agglomeration externalities can flourish.

Our empirical analysis obviously also points to the relevance of the utilized level of spatial aggregation or resolution. We have used the rather fine scale of municipalities in The Netherlands, and show that both population and employment dynamics are associated with non-negligible spatial spillover effects. Moreover, the dynamics partly occur at different spatial scales. Backward linkages are likely to be more geographically clustered than agglomeration externalities (see also 
Thissen et al. 2005). The latter easily take place within as well as between municipalities.

An obvious future extension in this dynamic adjustment model is to allow for heterogeneity in the population, for instance according to educational profile and skill level (human capital). Higher-skilled workers likely face thinner local labor markets and longer average commutes, and it is conceivable that higher-skilled workers are even less inclined to follow employment increases than lower-skilled workers. Until now, the empirical evidence for such dynamics is, however, rather scarce. Another line of future research, which is most likely particularly relevant in a European policy context, is to explicitly model the housing market, as in Vermeulen and van Ommeren (2007). Policy-makers are increasingly willing to liberalize the currently rather stringent spatial restrictions on housing development, and this will likely add another source of dynamics to future regional development of the population and employment.

\section{References}

Abdelrahman, H. M.: 1988, Product Differentiation, Monopolistic Competition and City Size, Regional Science and Urban Economics 18, 69-86.

Almeida, P. and Kogut, B.: 1999, Localization of knowledge and the mobility of engineers in regional networks, Management Science 45, 905-917.

Alonso, W.: 1964, Location and Land Use, Harvard University Press, Cambridge, Mass.

Amsterdambrief: 2011, Economic development perspectives for the northwing of the randstad. The Hague, Ministry of Economic Affairs (in Dutch).

Baldwin, R. E., Forslid, R., Martin, P., Ottaviano, G. I. P. and Robert-Nicoud, F.: 2003, Economic geography and public policy, Princeton University Press, Princeton.

Barca, F., McCann, P. and Roderiguez-Pose, A.: 2011, The case for regional development intervention: place-based versus place-neutral approaches, Journal of Regional Science pp. $\mathrm{x}-\mathrm{x}$.

Beaudry, C. and Schiffauerova, A.: 2009, Who's right, Marshall or Jacobs? The localization versus urbanization debate, Research Policy 38, 318-337.

Berg, J. J., Franke, S. and Reijndorp, A.: 2007, Adolescent Almere. How a city is made, NAi-Publishers, Rotterdam.

Boarnet, M. C.: 1994a, An empirical Model of Intrametropolitan Population and Employment Growth, Papers in Regional Science 73, 135-152.

Boarnet, M. C.: 1994b, The Monocentric Model and Employment Location, Journal of Urban Economics 36, 79-97.

Boarnet, M. C., Chalermpong, S. and Geho, E.: 2005, Specification issues in models of population and employment growth, Papers in Regional Science 84, 21-46.

Bollinger, C. R. and Ihlanfeldt, K. R.: 2003, The intraurban spatial distribution of employment: which government interventions make a difference?, Journal of Urban Economics 53, 396-412.

Bolton, R.: 1992, Place Prosperity Vs People Prosperity Revisited - An Old Issue with A New Angle, Urban Studies 29, 185-203. 
Briant, A., Combes, P. P. and Lafourcade, M.: 2010, Dots to boxes: Do the size and shape of spatial units jeopardize economic geography estimations?, Journal of Urban Economics 67, 287-302.

Brueckner, J.: 1978, Urban General Equilibrium Models with Non-central production, Journal of Regional Science 18, 203-215.

Carlino, G. A. and Mills, E. S.: 1987, The Determinants of Country Growth, Journal of Regional Science 27, 39-54.

Carruthers, J. I. and Mulligan, G. F.: 2007, Land absorption in US metropolitan areas: Estimates and projections from regional adjustment models, Geographical Analysis 39, 78-104.

Carruthers, J. I. and Mulligan, G. F.: 2008, A locational analysis of growth and change in American metropolitan areas, Papers in Regional Science 87, 155-171.

Carruthers, J. I. and Vias, A. C.: 2005, Urban, suburban, and exurban sprawl in the Rocky Mountain West: Evidence from regional adjustment models, Journal of Regional Science 45, 21-48.

CPB: 2009, Cost-benefit analysis of urbanisation and public transport alternatives for Almere, Netherlands Bureau for Economic Policy Analysis (CPB; in Dutch), The Hague.

de Groot, H. L. F., Poot, J. and Smit, M. J.: 2009, Agglomeration externalities, innovation and regional growth: theoretical perspectives and meta-analysis, in P. Nijkamp and R. Capello (eds), Handbook of regional growth and development theories, Edward Elgar, chapter 14, pp. 256-281.

de Groot, H., Marlet, G., Teulings, C. N. and Vermeulen, W.: 2010, City and countryside. The Hague, Netherland Bureau for Economic Policy Analysis (in Dutch).

de Vor, F. and de Groot, H. L. F.: 2010, Agglomeration externalities and localized employment growth: the performance of industrial sites in Amsterdam, Annals of Regional Science 44, 409-431.

Duranton, G. and Overman, H. G.: 2005, Testing for localization using micro-geographic data, Review of Economic Studies 72, 1077-1106.

Duranton, G. and Puga, D.: 2000, Diversity and specialisation in cities: Why, where and when does it matter?, Urban Studies 37, 533-555.

Duranton, G. and Puga, D.: 2004, Micro-foundations of urban agglomeration economies, in J. V. Henderson and J. F. Thisse (eds), Handbook of Regional and Urban Economics, Elsevier, chapter 48, pp. 2063-2117.

Frenken, K., van Oort, F. G. and Verburg, T.: 2007, Related variety, unrelated variety and regional economic growth, Regional Studies 41, 685-697.

Fujita, M.: 1989, Urban Economic Theory: Land Use and City Size, Cambridge University Press, Cambridge.

Fujita, M., Krugman, P. and Venables, A. J.: 1999, The Spatial Economy: Cities, Regions, and Economic Trade, MIT Press, Cambridge.

Glaeser, E. L., Kallal, H. D., Scheinkman, J. A. and Schleifer, A.: 1992, Growth in Cities, Journal of Political Economy 100, 1126-1152.

Graves, P. E.: 1983, Migration with a composite amenity; the role of rents, Journal of Regional Science 23, $541-546$.

Haughwout, A. F.: 2010, Management of Large City Regions: Designing Efficient Metropolitan Fiscal Policies, Journal of Regional Science 50, 401-421.

Henderson, V.: 1997, Externalities and industrial development, Journal of Urban Economics 42, 449-470. 
Henderson, V., Kuncoro, A. and Turner, M.: 1995, Industrial-Development in Cities, Journal of Political Economy 103, 1067-1090.

Hoogstra, G. J., Florax, R. J. G. M. and van Dijk, J.: 2005, Do 'jobs follow people' or 'people follow jobs'? a meta-analysis of carlino-mills studies. Working paper, Universiteit Groningen.

Hoogstra, G. J., van Dijk, J. and Florax, R. J. G. M.: 2011, Determinants of Variation in PopulationEmployment Interaction Findings: A Quasi-Experimental Meta-Analysis, Geographical Analysis 43, 1437.

Irwin, E. G.: 2010, New Directions for Urban Economic Models of Land Use Change: Incorporating Spatial Dynamics and Heterogeneity, Journal of Regional Science 50, 65-91.

Kelejian, H. H. and Prucha, I. R.: 1998, A Generalized Spatial Two-Stage Least Squares Procedure for Estimating a Spatial Autoregressive Model with Autoregressive Disturbances, Journal of Real Estate Finance and Economics 17, 99-121.

Kelejian, H. H. and Prucha, I. R.: 2004, Estimation of Simultaneous Systems of Spatially Interrelated Cross Sectional Equations, Journal of Econometrics 118, 27-50.

Klepper, S.: 2007, Disagreements, spinoffs, and the evolution of Detroit as the capital of the US automobile industry, Management Science 53, 616-631.

Lissoni, F.: 2001, Knowledge codification and the geography of innovation: the case of Brescia mechanical cluster, Research Policy 30, 1479-1500.

McCann, P. and van Oort, F.: 2009, Theories of agglomeration and regional economic growth: a historical review, Handbook of Regional Growth and Development Theories, Edward Elgar, chapter Nijkamp, P. and Capello, R., pp. 19-32.

Melo, P. C., Graham, D. J. and Noland, R. B.: 2010, A meta-analysis of estimates of urban agglomeration economies, Regional Science and Urban Economics 39, 332-342.

Muth, R. F.: 1969, Cities and Housing, The University of Chicago Press, Chicago.

Ponds, R., van Oort, F. and Frenken, K.: 2010, Innovation, spillovers and university-industry collaboration: an extended knowledge production function approach, Journal of Economic Geography 10, 231-255.

Puga, D.: 2010, The Magnitude and Causes of Agglomeration Economies*, Journal of Regional Science 50, 203-219.

Roback, J.: 1982, Wages, rents and the quality of life, Journal of Political Economy 90, 1257-1278.

Rosenthal, S. S. and Strange, W. C.: 2001, The determinants of agglomeration, Journal of Urban Economics 59, 191-229.

Rosenthal, S. S. and Strange, W. C.: 2004, Evidence on the nature and sources of agglomeration economies, in J. V. Henderson and J. F. Thisse (eds), Handbook of Regional and Urban Economics, Elsevier, chapter 49, pp. 2119-2171.

Sohn, J. and Hewings, G. J. D.: 2000, Spatial evidence of agglomeration economies in chicago. Working paper.

Steinnes, D. N.: 1977, 'Do people follow jobs' or 'do jobs follow people'? A causality issue in urban economics, Journal of Urban Economics 4, 69-79.

Storper, M. and Venables, A. J.: 2004, Buzz: face-to-face contact and the urban economy, Journal of Economic Geography 4, 351-370.

Structuurvisie: 2008, Structuurvisie randstad 2040. The Hague, Ministry of Housing, Spatial Planning and the Environment. 
Thisse, J. F.: 2010, Toward A Unified Theory of Economic Geography and Urban Economics, Journal of Regional Science 50, 281-296.

Thissen, M.: 2005, Raem: Regional applied general equilibrium model for the netherlands, A survey of spatial planning models in the Netherlands: theory, application and evaluation, NAi Publishers, chapter van Oort, F., Thissen, M., and van Wissen, L., pp. 65-86.

Thissen, M., van Oort, F. and van Wissen, L.: 2005, A survey of spatial economic planning models in the Netherlands. Theory, application and evualation, NAi-publishers, Rotterdam.

van Oort, F., Burger, M. and Raspe, O.: 2010, On the Economic Foundation of the Urban Network Paradigm: Spatial Integration, Functional Integration and Economic Complementarities within the Dutch Randstad, Urban Studies 47, 725-748.

van Oort, F. G.: 2007, Spatial and Sectoral Decomposition Effects of Agglomeration Economies in the Netherlands, Papers in Regional Science 86, 5-30.

Venables, A. J.: 1996, Equilibrium locations of vertically linked industries, International Economic Review 37, 341-359.

Vermeulen, W. and Rouwendal, J.: 2007, Housing supply and land use regulation in the netherlands. Tinbergen Institute Discussion Paper, TI 2007-058/3, Amsterdam.

Vermeulen, W. and van Ommeren, J.: 2007, Housing supply and the interaction of regional population and employment. CPB Discussion Paper, no. 65, The Hague.

Wheaton, W. C.: 2004, Commuting, congestion and employment dispersal in cities with mixed land use, Journal of Urban Economics 55, 417-439. 
Table 3: Generalized spatial 3SLS estimation results with asymptotic standard errors in parentheses $(N=5316)$

\begin{tabular}{|c|c|c|c|c|c|c|c|c|}
\hline Variabele & $\Delta$ Pop & $\Delta \mathrm{Agr}$ & $\Delta$ Ind & $\Delta \log$ & $\Delta$ Ret & $\Delta$ Con & $\Delta$ Pro & $\Delta$ Gov \\
\hline$\rho \times \mathbf{W}$ & $\begin{array}{r}0.1471 \\
(0.059)\end{array}$ & $\begin{array}{r}0.3133 \\
(0.1801)\end{array}$ & $\begin{array}{l}-0.2965 \\
(0.1285)\end{array}$ & $\begin{array}{l}-0.0208 \\
(0.1326)\end{array}$ & $\begin{array}{r}0.1348 \\
(0.1301)\end{array}$ & $\begin{array}{r}-0.1991 \\
(0.1374)\end{array}$ & $\begin{array}{l}-0.1875 \\
(0.0982)\end{array}$ & $\begin{array}{c}-0.1664 \\
(0.1226)\end{array}$ \\
\hline$\gamma_{p o p}$ & & $\begin{array}{r}0.9508 \\
(0.8754)\end{array}$ & $\begin{array}{l}-0.1023 \\
(0.3251)\end{array}$ & $\begin{array}{r}-0.2400 \\
(0.3882)\end{array}$ & $\begin{array}{r}0.7060 \\
(0.2610)\end{array}$ & $\begin{array}{r}0.0114 \\
(0.3364)\end{array}$ & $\begin{array}{r}0.6527 \\
(0.4754)\end{array}$ & $\begin{array}{r}0.2543 \\
(0.3624)\end{array}$ \\
\hline$\gamma_{a g r}$ & $\begin{array}{r}0.0168 \\
(0.0085)\end{array}$ & & $\begin{array}{l}-0.0687 \\
(0.0525)\end{array}$ & $\begin{array}{r}0.0270 \\
(0.0587)\end{array}$ & $\begin{array}{r}0.0366 \\
(0.0436)\end{array}$ & $\begin{array}{r}0.0467 \\
(0.0518)\end{array}$ & $\begin{array}{r}0.1026 \\
(0.0729)\end{array}$ & $\begin{array}{r}-0.0523 \\
(0.0574)\end{array}$ \\
\hline$\gamma_{\text {ind }}$ & $\begin{array}{r}-0.0753 \\
(0.0221)\end{array}$ & $\begin{array}{l}-0.7795 \\
(0.4121)\end{array}$ & & $\begin{array}{r}0.4711 \\
(0.1584)\end{array}$ & $\begin{array}{l}-0.2203 \\
(0.1159)\end{array}$ & $\begin{array}{l}-0.1012 \\
(0.1459)\end{array}$ & $\begin{array}{l}-0.5054 \\
(0.1909)\end{array}$ & $\begin{array}{r}0.4426 \\
(0.1423)\end{array}$ \\
\hline$\gamma_{\log }$ & $\begin{array}{r}0.0384 \\
(0.0177)\end{array}$ & $\begin{array}{r}0.6801 \\
(0.2819)\end{array}$ & $\begin{array}{r}0.2205 \\
(0.0952)\end{array}$ & & $\begin{array}{r}0.0814 \\
(0.0810)\end{array}$ & $\begin{array}{r}0.0503 \\
(0.1061)\end{array}$ & $\begin{array}{r}0.1387 \\
(0.1473)\end{array}$ & $\begin{array}{r}-0.1610 \\
(0.1151)\end{array}$ \\
\hline$\gamma_{r e t}$ & $\begin{array}{r}0.0022 \\
(0.0269)\end{array}$ & $\begin{array}{c}-0.0604 \\
(0.3874)\end{array}$ & $\begin{array}{l}-0.2161 \\
(0.1524)\end{array}$ & $\begin{array}{l}-0.1591 \\
(0.1835)\end{array}$ & & $\begin{array}{r}0.0182 \\
(0.1595)\end{array}$ & $\begin{array}{r}0.3121 \\
(0.2209)\end{array}$ & $\begin{array}{r}0.2006 \\
(0.1692)\end{array}$ \\
\hline$\gamma_{\text {con }}$ & $\begin{array}{c}-0.0226 \\
(0.0237)\end{array}$ & $\begin{array}{c}-0.1531 \\
(0.3636)\end{array}$ & $\begin{array}{c}-0.3392 \\
(0.1460)\end{array}$ & $\begin{array}{r}0.0014 \\
(0.1750)\end{array}$ & $\begin{array}{l}-0.2650 \\
(0.1131)\end{array}$ & & $\begin{array}{r}0.0055 \\
(0.2156)\end{array}$ & $\begin{array}{l}-0.0709 \\
(0.1664)\end{array}$ \\
\hline$\gamma_{\text {pro }}$ & $\begin{array}{r}-0.0077 \\
(0.0119)\end{array}$ & $\begin{array}{c}-0.1259 \\
(0.1835)\end{array}$ & $\begin{array}{c}-0.1921 \\
(0.0719)\end{array}$ & $\begin{array}{r}0.2809 \\
(0.0860)\end{array}$ & $\begin{array}{r}0.0134 \\
(0.0565)\end{array}$ & $\begin{array}{r}0.0615 \\
(0.0765)\end{array}$ & & $\begin{array}{r}0.1615 \\
(0.0785)\end{array}$ \\
\hline$\gamma_{g o v}$ & $\begin{array}{l}-0.0852 \\
(0.0204)\end{array}$ & $\begin{array}{r}0.3116 \\
(0.3376)\end{array}$ & $\begin{array}{r}0.3929 \\
(0.1183)\end{array}$ & $\begin{array}{r}-0.3430 \\
(0.1568)\end{array}$ & $\begin{array}{r}0.2048 \\
(0.1032)\end{array}$ & $\begin{array}{l}-0.1034 \\
(0.1362)\end{array}$ & $\begin{array}{r}0.4326 \\
(0.1816)\end{array}$ & \\
\hline$\alpha_{p o p}$ & & $\begin{array}{r}0.0224 \\
(0.0218)\end{array}$ & $\begin{array}{r}0.0082 \\
(0.0078)\end{array}$ & $\begin{array}{r}0.0067 \\
(0.0097)\end{array}$ & $\begin{array}{r}0.0178 \\
(0.0062)\end{array}$ & $\begin{array}{r}0.0079 \\
(0.0078)\end{array}$ & $\begin{array}{l}-0.0017 \\
(0.0110)\end{array}$ & $\begin{array}{r}0.0105 \\
(0.0088)\end{array}$ \\
\hline$\alpha_{a g r}$ & $\begin{array}{r}0.0015 \\
(0.0005)\end{array}$ & & $\begin{array}{r}-0.0004 \\
(0.0031)\end{array}$ & $\begin{array}{r}0.0031 \\
(0.0038)\end{array}$ & $\begin{array}{r}0.0022 \\
(0.0028)\end{array}$ & $\begin{array}{r}0.0037 \\
(0.0032)\end{array}$ & $\begin{array}{r}0.0058 \\
(0.0045)\end{array}$ & $\begin{array}{r}-0.0059 \\
(0.0036)\end{array}$ \\
\hline$\alpha_{\text {ind }}$ & $\begin{array}{r}-0.0020 \\
(0.0007)\end{array}$ & $\begin{array}{l}-0.0275 \\
(0.0116)\end{array}$ & & $\begin{array}{r}0.0172 \\
(0.0043)\end{array}$ & $\begin{array}{l}-0.0016 \\
(0.0034)\end{array}$ & $\begin{array}{l}-0.0052 \\
(0.0041)\end{array}$ & $\begin{array}{l}-0.0085 \\
(0.0057)\end{array}$ & $\begin{array}{r}0.0075 \\
(0.0045)\end{array}$ \\
\hline$\alpha_{\log }$ & $\begin{array}{r}0.0030 \\
(0.0007)\end{array}$ & $\begin{array}{r}0.0319 \\
(0.0124)\end{array}$ & $\begin{array}{r}0.0190 \\
(0.0039)\end{array}$ & & $\begin{array}{r}0.0095 \\
(0.0036)\end{array}$ & $\begin{array}{r}0.0016 \\
(0.0046)\end{array}$ & $\begin{array}{r}0.0191 \\
(0.0058)\end{array}$ & $\begin{array}{r}-0.0080 \\
(0.0049)\end{array}$ \\
\hline$\alpha_{\text {ret }}$ & $\begin{array}{r}-0.0005 \\
(0.0016)\end{array}$ & $\begin{array}{r}0.0292 \\
(0.0255)\end{array}$ & $\begin{array}{r}0.0089 \\
(0.0088)\end{array}$ & $\begin{array}{l}-0.0158 \\
(0.0111)\end{array}$ & & $\begin{array}{r}0.0083 \\
(0.0091)\end{array}$ & $\begin{array}{r}0.0230 \\
(0.0128)\end{array}$ & $\begin{array}{r}0.0038 \\
(0.0103)\end{array}$ \\
\hline$\alpha_{\text {con }}$ & $\begin{array}{c}-0.0015 \\
(0.0010)\end{array}$ & $\begin{array}{r}-0.0145 \\
(0.0161)\end{array}$ & $\begin{array}{c}-0.0158 \\
(0.0061)\end{array}$ & $\begin{array}{r}0.0035 \\
(0.0075)\end{array}$ & $\begin{array}{l}-0.0052 \\
(0.0049)\end{array}$ & & $\begin{array}{r}0.0018 \\
(0.0091)\end{array}$ & $\begin{array}{r}0.0016 \\
(0.0071)\end{array}$ \\
\hline$\alpha_{\text {pro }}$ & $\begin{array}{r}-0.0007 \\
(0.0010)\end{array}$ & $\begin{array}{l}-0.0028 \\
(0.0167)\end{array}$ & $\begin{array}{c}-0.0118 \\
(0.0061)\end{array}$ & $\begin{array}{r}0.0261 \\
(0.0073)\end{array}$ & $\begin{array}{r}0.0041 \\
(0.0051)\end{array}$ & $\begin{array}{r}0.0186 \\
(0.0059)\end{array}$ & & $\begin{array}{r}0.0197 \\
(0.0064)\end{array}$ \\
\hline$\alpha_{g o v}$ & $\begin{array}{r}0.0029 \\
(0.0008)\end{array}$ & $\begin{array}{c}-0.0148 \\
(0.0136)\end{array}$ & $\begin{array}{r}0.0083 \\
(0.0052)\end{array}$ & $\begin{array}{l}-0.0137 \\
(0.0062)\end{array}$ & $\begin{array}{r}0.0097 \\
(0.0042)\end{array}$ & $\begin{array}{l}-0.0033 \\
(0.0053)\end{array}$ & $\begin{array}{r}0.0168 \\
(0.0071)\end{array}$ & \\
\hline$\lambda$ & $\begin{array}{c}-0.0014 \\
(0.0013)\end{array}$ & $\begin{array}{r}-0.0500 \\
(0.0050)\end{array}$ & $\begin{array}{c}-0.0175 \\
(0.0033)\end{array}$ & $\begin{array}{c}-0.0252 \\
(0.0044)\end{array}$ & $\begin{array}{l}-0.0359 \\
(0.0051)\end{array}$ & $\begin{array}{l}-0.0327 \\
(0.0034)\end{array}$ & $\begin{array}{l}-0.0497 \\
(0.0063)\end{array}$ & $\begin{array}{r}-0.0292 \\
(0.0037)\end{array}$ \\
\hline$\beta$ & & & & & & & & \\
\hline$\%<25 \mathrm{jr}$ & $\begin{array}{r}8.60-05 \\
(8.48 \mathrm{E}-05)\end{array}$ & & & & & & & \\
\hline$\%>65 \mathrm{jr}$ & $\begin{array}{r}4.18-05 \\
(0.0001)\end{array}$ & & & & & & & \\
\hline$\Delta$ Housing supply & $\begin{array}{r}3.96 \mathrm{E}-06 \\
(7.93 \mathrm{E}-07)\end{array}$ & & & & & & & \\
\hline Size & $\begin{array}{r}-1.42 \mathrm{E}-07 \\
(3.62 \mathrm{E}-08)\end{array}$ & $\begin{array}{r}5.94 \mathrm{E}-07 \\
(6.52 \mathrm{E}-07)\end{array}$ & $\begin{array}{r}2.60 \mathrm{E}-08 \\
(2.18 \mathrm{E}-07)\end{array}$ & $\begin{array}{r}-2.72 \mathrm{E}-07 \\
(2.73 \mathrm{E}-07)\end{array}$ & $\begin{array}{r}-3.33-07 \\
(1.95 \mathrm{E}-07)\end{array}$ & $\begin{array}{c}-2.53 \mathrm{E}-07 \\
(2.96 \mathrm{E}-07)\end{array}$ & $\begin{array}{c}-2.04 \mathrm{E}-07 \\
(3.03 \mathrm{E}-07)\end{array}$ & $\begin{array}{r}-9.97 \mathrm{E}-09 \\
(2.46-07)\end{array}$ \\
\hline Surface water & $\begin{array}{r}6.02 \mathrm{E}-05 \\
(4.95 \mathrm{E}-05)\end{array}$ & $\begin{array}{r}-0.0005 \\
(0.0009)\end{array}$ & $\begin{array}{r}0.0004 \\
(0.0003)\end{array}$ & $\begin{array}{r}-0.0002 \\
(0.0004)\end{array}$ & $\begin{array}{r}0.0004 \\
(0.0003)\end{array}$ & $\begin{array}{r}0.0004 \\
(0.0003)\end{array}$ & $\begin{array}{r}0.0006 \\
(0.0004)\end{array}$ & $\begin{array}{r}-0.0006 \\
(0.0003)\end{array}$ \\
\hline Agriculture & $\begin{array}{r}7.04 \mathrm{E}-05 \\
(2.49 \mathrm{E}-05)\end{array}$ & $\begin{array}{r}0.0009 \\
(0.0004)\end{array}$ & $\begin{array}{r}0.0005 \\
(0.0001)\end{array}$ & $\begin{array}{r}-0.0003 \\
(0.0002)\end{array}$ & $\begin{array}{r}0.0002 \\
(0.0001)\end{array}$ & $\begin{array}{r}0.0002 \\
(0.0001)\end{array}$ & $\begin{array}{r}0.0005 \\
(0.0002)\end{array}$ & $\begin{array}{r}-0.0003 \\
(0.0002)\end{array}$ \\
\hline Natural areas \& recr. & $\begin{array}{r}8.66 \mathrm{E}-05 \\
(3.20 \mathrm{E}-05)\end{array}$ & $\begin{array}{r}0.0012 \\
(0.0006)\end{array}$ & $\begin{array}{r}0.0006 \\
(0.0002)\end{array}$ & $\begin{array}{l}-0.0004 \\
(0.0002)\end{array}$ & $\begin{array}{r}0.0001 \\
(0.0002)\end{array}$ & $\begin{array}{r}0.0004 \\
(0.0002)\end{array}$ & $\begin{array}{r}0.0005 \\
(0.0003)\end{array}$ & $\begin{array}{r}-0.0003 \\
(0.0002)\end{array}$ \\
\hline Semi-buildup areas & $\begin{array}{r}0.0008 \\
(0.0002)\end{array}$ & $\begin{array}{l}-0.0040 \\
(0.0030)\end{array}$ & $\begin{array}{r}0.0005 \\
(0.0010)\end{array}$ & $\begin{array}{r}0.0023 \\
(0.0012)\end{array}$ & $\begin{array}{l}-0.0005 \\
(0.0009)\end{array}$ & $\begin{array}{r}0.0016 \\
(0.0010)\end{array}$ & $\begin{array}{l}-0.0002 \\
(0.0014)\end{array}$ & $\begin{array}{r}0.0003 \\
(0.0011)\end{array}$ \\
\hline Transport infrastr. & $\begin{array}{c}-0.0003 \\
(0.0002)\end{array}$ & $\begin{array}{r}0.0071 \\
(0.0032)\end{array}$ & $\begin{array}{r}0.0017 \\
(0.0011)\end{array}$ & $\begin{array}{l}-0.0036 \\
(0.0014)\end{array}$ & $\begin{array}{r}0.0007 \\
(0.0010)\end{array}$ & $\begin{array}{r}-1.48 \mathrm{E}-05 \\
(0.0011)\end{array}$ & $\begin{array}{r}0.0038 \\
(0.0015)\end{array}$ & $\begin{array}{r}-0.0013 \\
(0.0012)\end{array}$ \\
\hline$\Delta$ Industrial sites & & $\begin{array}{r}-0.0005 \\
(0.0008)\end{array}$ & $\begin{array}{r}0.0007 \\
(0.0002)\end{array}$ & $\begin{array}{r}-0.0003 \\
(0.0003)\end{array}$ & $\begin{array}{r}0.0004 \\
(0.0002)\end{array}$ & $\begin{array}{r}0.0004 \\
(0.0003)\end{array}$ & $\begin{array}{r}0.0006 \\
(0.0004)\end{array}$ & $\begin{array}{r}-0.0009 \\
(0.0003)\end{array}$ \\
\hline$\varphi$ & -0.0992 & -0.4184 & -0.1086 & -0.2235 & -0.3752 & -0.0534 & -0.0459 & -0.1247 \\
\hline
\end{tabular}




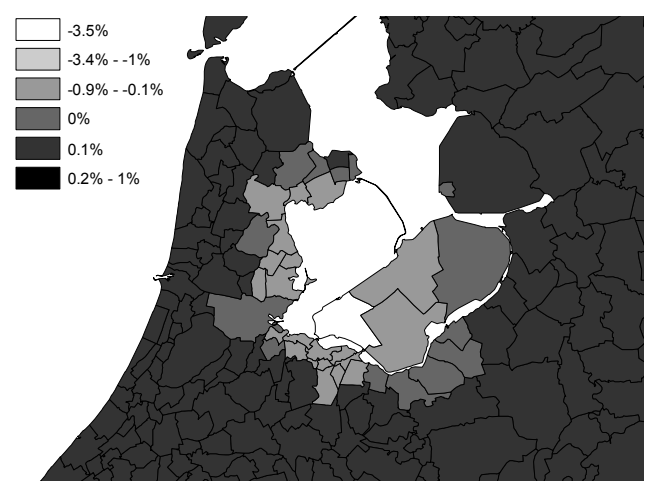

(a) Agriculture

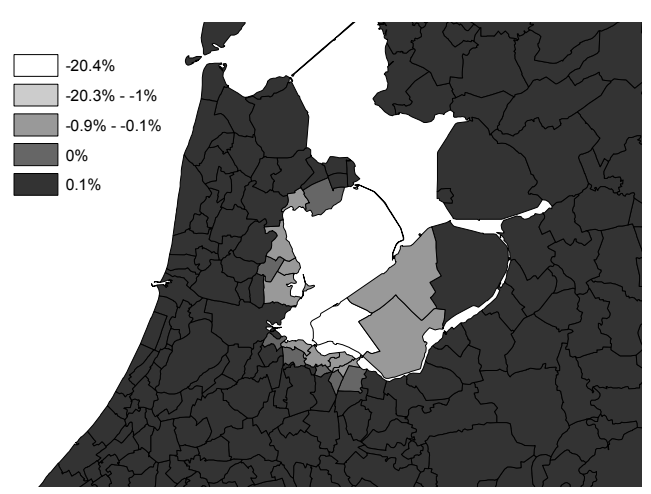

(c) Logistics

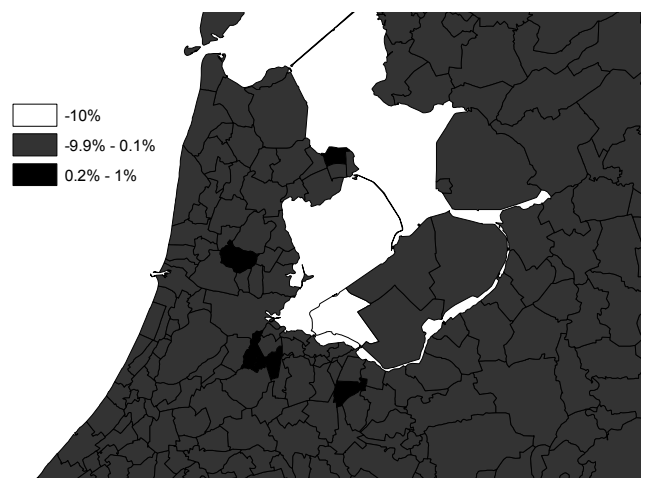

(e) Consumer services

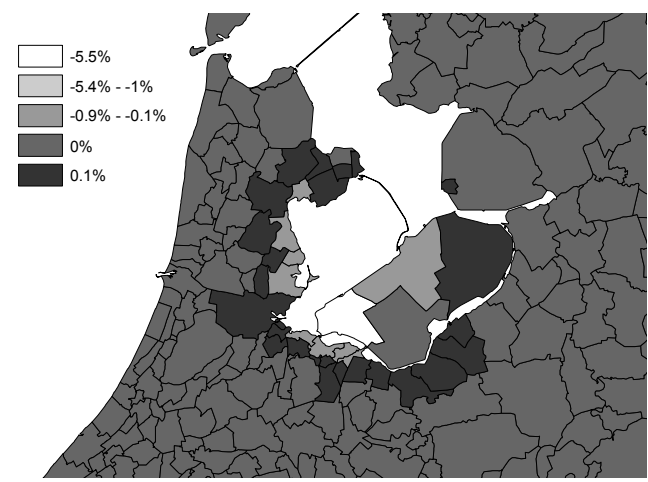

(b) Industry

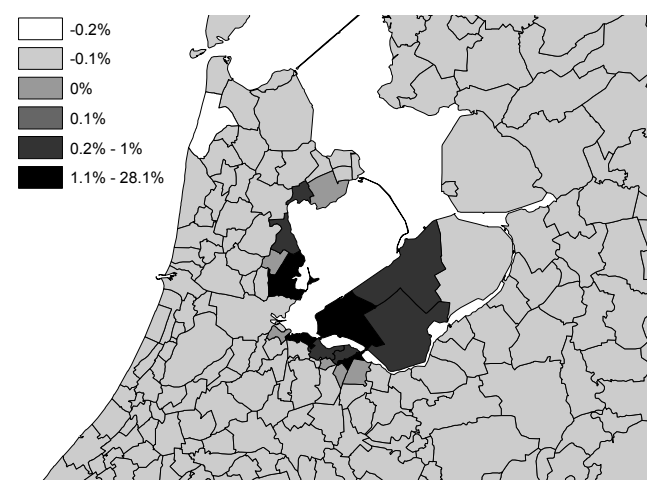

(d) Retail

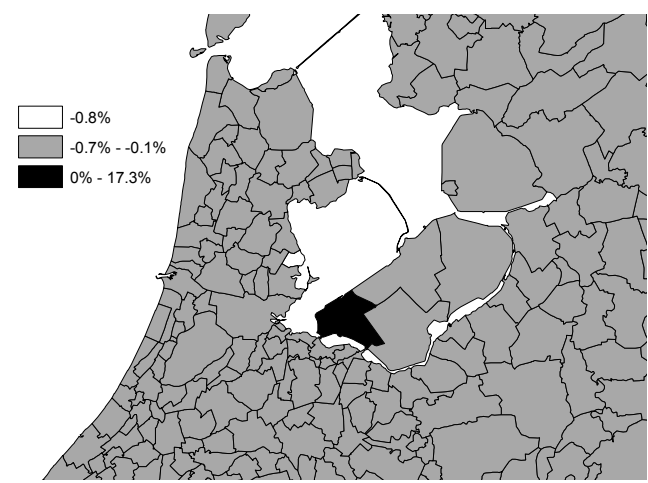

(f) Producer services

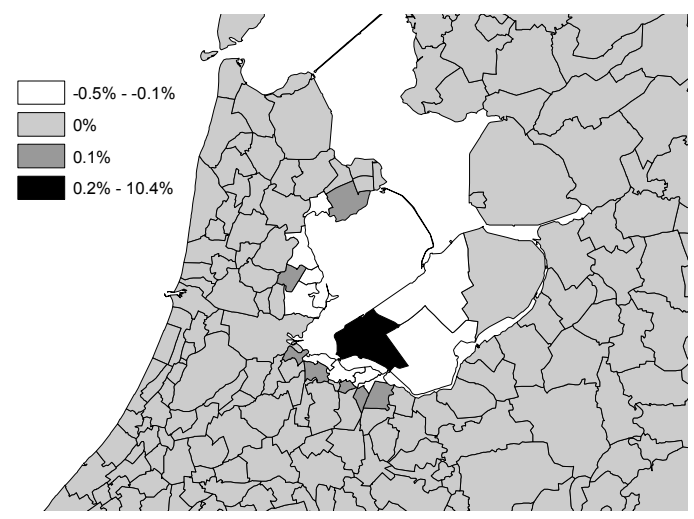

(g) Government, education and health care

Figure 3: Sectoral employment changes (in percentage point differences) when 60,000 dwellings are built in the municipality of Almere over a period of 20 years 